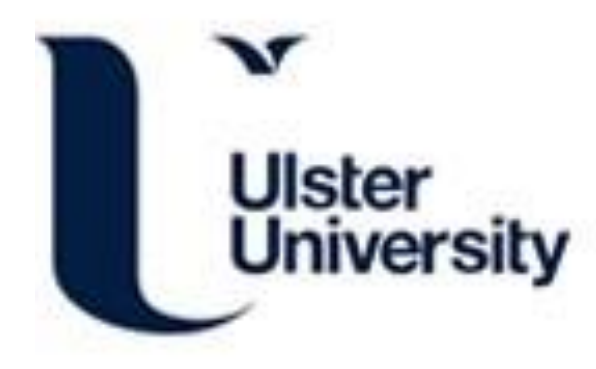

\title{
Distinguishing Complex PTSD from Borderline Personality Disorder among individuals with a history of sexual trauma; a latent class analysis
}

Frost, R., Hyland, P., Shevlin, M., \& Murphy, J. (2018). Distinguishing Complex PTSD from Borderline

Personality Disorder among individuals with a history of sexual trauma; a latent class analysis. European Journal of Truama and Dissociation. https://doi.org/10.1016/j.ejtd.2018.08.004

Link to publication record in Ulster University Research Portal

Published in:

European Journal of Truama and Dissociation

Publication Status:

Published online: 31/08/2018

DOI:

10.1016/j.ejtd.2018.08.004

Document Version

Author Accepted version

\section{General rights}

Copyright for the publications made accessible via Ulster University's Research Portal is retained by the author(s) and / or other copyright owners and it is a condition of accessing these publications that users recognise and abide by the legal requirements associated with these rights.

\section{Take down policy}

The Research Portal is Ulster University's institutional repository that provides access to Ulster's research outputs. Every effort has been made to ensure that content in the Research Portal does not infringe any person's rights, or applicable UK laws. If you discover content in the Research Portal that you believe breaches copyright or violates any law, please contact pure-support@ulster.ac.uk. 
Title: Distinguishing Complex PTSD from Borderline Personality Disorder among individuals with a history of sexual trauma; a latent class analysis.

Rachel Frost1,4, Philip Hyland2, 3, 4, Mark Shevlin1, 4, \& Jamie Murphy1, 4.

1School of Psychology, Ulster University, Derry, Northern Ireland.

2National College of Ireland, Dublin, Republic of Ireland.

3Centre for Global Health, Trinity College Dublin, Dublin, Republic of Ireland 4The Collaborative Network for Training and Excellence in Psychotraumatology (CONTEXT), www.psychotraumanetwork.com

Running title: Distinguishing CPTSD and BPD

Corresponding Author: Rachel Frost, Ulster University, Magee Campus, Derry, Northland Road, Northern Ireland, BT48 7JL. Contact: r.frost@ulster.ac.uk

Phone number: +442871675169 


\begin{abstract}
Introduction; There has been debate regarding whether Complex PTSD (CPTSD) is conceptually distinct from Borderline Personality Disorder (BPD).

Objective: To assess whether ICD-11 CPTSD was distinguishable from BPD in a sample of sexual assault survivors.

Method: A subsample of individuals $(\mathrm{n}=956)$, that selected sexual assault as an index trauma, were selected from a U.S. general population survey dataset. The distribution of PTSD, CPTSD and BPD symptomology was evaluated using latent class analysis (LCA). Multinomial logistic regression analyses were performed to evaluate whether various forms of child maltreatment and cumulative child maltreatment could discriminate between classes. Results: CPTSD emerged as a distinct symptom profile within the sample. Conversely, BPD symptomology was evident in two classes but was accompanied by PTSD/CPTSD symptomology in each. Overall, five classes were identified that differed both quantitatively and qualitatively. Cumulative childhood maltreatment and physical neglect predicted CPTSD class membership.
\end{abstract}

Conclusion: The findings suggest that CPTSD is distinct from BPD among a sample of individuals who have been shown to be at significant risk for both diagnoses. Further research is required to identify factors that distinguish CPTSD from BPD.

Key words: post-traumatic stress; complex posttraumatic stress; ICD-11; borderline personality disorder; sexual assault. 


\section{Introduction}

The $11^{\text {th }}$ version of the International Classification of Diseases manual (ICD-11) will formally recognise Complex Posttraumatic Stress Disorder (CPTSD), when officially released in 2018. There are concerns surrounding the validity of CPTSD, particularly in relation to Borderline Personality Disorder (BPD). The two disorders may be at risk of potential symptom overlap, as both measure variants of affect dysregulation, disturbed relationships, and negative self-evaluation (Resick et al., 2012). Additionally, both disorders tend to emerge in particular trauma contexts, notably among those with a history of sexual victimisation (de Aquino Ferreira, Queiroz Pereira, Neri Benevides, \& Aguiar Melo, 2018; Ford \& Courtois, 2014; Frias \& Palma, 2015; Hyland et al., 2017; Resick et al., 2012). Research is necessary to establish whether there is sufficient conceptual distinction between CPTSD and BPD, especially among those with a history of sexual violence.

It has been speculated that CPTSD represents a combination of PTSD and (DSM-IV) BPD symptoms given the high rates of comorbidity between these diagnoses (Cloitre, Garvert, Weiss, Carlson, \& Bryant, 2014). In non-clinical samples, BPD/PTSD comorbidity has ranged from $2 \%$ to $32 \%$, depending upon the use of current or lifetime diagnostic rates for PTSD (Grant et al., 2008; Pagura et al., 2010; Scheiderer, Wood, \& Trull, 2015), while in clinical samples the rate of BPD/PTSD comorbidity is higher, ranging from $25 \%$ to $68 \%$ (Harned, Rizvi, \& Linehan, 2010; Heffernan \& Cloitre, 2000; Zanarini et al., 1998; Zlotnick, Franklin, \& Zimmerman, 2002). Where attempts have been made to differentiate between CPTSD and BPD evidence suggests that CPTSD and BPD are distinct diagnostic entities. For example, Cloitre et al. (2014), examined differences between CPTSD, PTSD and BPD using latent class analysis (LCA) among a female treatment-seeking sample of survivors of childhood abuse. Four latent classes (groups of individuals characterised by common 
symptom patterns) were identified; a CPTSD class; a BPD class; a PTSD class; and a baseline/low symptom class. In another study, Knefel, Tran, and Lueger-Schuster (2016), used network analysis to explore symptom connectivity between PTSD, CPTSD, and BPD symptoms among an adult sample of institutional child abuse survivors. BPD symptoms were found not to be strongly connected to other symptoms in the network, suggesting that BPD symptoms were distinct from PTSD and CPTSD symptoms.

CPTSD is predominantly characterised by symptom clusters collectively defined as 'Disturbances in Self Organisation' (DSO) which include affective dysregulation, negative self-concept, and disturbed relationships (Maercker et al., 2013). Disruptions to self-concept, relational, and affective regulation capacity are also evident in DSM-IV BPD symptomatology. While these symptom dimensions are labelled similarly, Cloitre et al. (2014), suggest that phenomenological distinctions differentiate symptoms of CPTSD from those that characterise BPD. For instance, relational disturbances in BPD reflect sustained chaotic engagement, whereas, CPTSD is characterised by fearful or chronic avoidance of relationships. Additionally, BPD is characterised by a shifting or an unstable self-image, whereas CPTSD is characterised as a consistently negative self-concept. In CPTSD, affect dysregulation does not include suicidal and self-injurious behaviours as core symptoms which are a defining characteristic of BPD. Furthermore, fear of rejection or abandonment, and feelings of emptiness, impulsivity and paranoid dissociation are symptoms unique to BPD.

ICD-11 CPTSD has been found to manifest following sustained interpersonal trauma exposure and cumulative trauma exposure in a dose-response manner, with trauma occurring during developmental periods creating a particular vulnerability (Ben-Ezra et al., 2018; Cloitre, Garvert, Brewin, Bryant, \& Maercker, 2013; Gilbar, Hyland, Cloitre, \& Dekel, 2018; Hyland et al., 2017; Karatzias et al., 2016; Maercker, Hecker, Augsburger, \& Kliem, 2018; 
Shevlin et al., 2017). Literature concerning the prevalence of sexual violence consistently indicates that victimisation is likely to begin during early development (Basile \& Smith, 2011). Moreover, childhood sexual abuse is likely to co-occur with multiple forms of maltreatment including physical and emotional abuse as well as neglect (Finkelhor, Turner, Shattuck, \& Hamby, 2013). Although trauma exposure is not a requirement for a BPD diagnosis, BPD severity demonstrates a dose response relationship with stressful life events (Shevlin, Dorahy, Adamson, \& Murphy, 2007). In addition, childhood sexual assault may constitute a key etiological risk factor for the disorder (for a recent review see de Aquino Ferreira et al., 2018). Yet, trauma may be neither necessary nor sufficient to explain the development of borderline pathology, researchers have also emphasised other key risk factors including emotional maltreatment (childhood emotional abuse, neglect, and poor caregiving) and predisposing temperamental vulnerabilities (Lieb, Zanarini, Schmahl, Linehan, \& Bohus, 2004; Scheiderer et al., 2015; Zanarini \& Frankenburg, 1997; Zanarini et al., 1997).

The current study sought to determine whether CPTSD would emerge as a distinct construct in a context where CPTSD and BPD symptomology would be likely to manifest; namely among victims of sexual assault. Given the validity issues surrounding the new CPTSD diagnosis and considering the proposed phenomenological similarity between CPTSD and BPD symptomology, it was important to evaluate the constructs at a symptom level. We hypothesised that LCA would identify several distinct groups of trauma survivors including (but not limited to) groups characterised by: (1) a CPTSD symptom profile (high probability of endorsing PTSD and DSO symptoms, but a low probability of endorsing BPD symptoms), (2) a BPD symptom profile (high probability of endorsing BPD symptoms but correspondingly low probabilities of endorsing DSO and PTSD symptoms), and a PTSD symptom profile (high probability of endorsing PTSD symptoms but correspondingly low probabilities of endorsing DSO and BPD symptoms). Second, it was hypothesised that the 
CPTSD group would be distinguishable from the remainder of the sample by higher levels of child maltreatment (sexual abuse, physical abuse, emotional abuse, emotional neglect, and physical neglect) as such experiences have been proposed to specifically differentiate CPTSD symptoms from alternative trauma response symptom spectra.

\section{Methods}

\subsection{Participants and Procedures}

Data for this study was drawn from the National Epidemiologic Survey on Alcohol and Related Conditions Wave II (NESARC-II). NESARC Wave II involved face-to-face interviews with 34,653 of the original Wave I participants $(70.2 \%$ response rate) - Wave II data was weighted to reflect the original design sampling characteristics (Hasin \& Grant, 2015). NESARC assessed the prevalence, course, and risk factors, of psychiatric disorders, among a nationally representative civilian non-institutionalized sample of adults ( $\geq 18$ years) living in the United States (see Hasin \& Grant, 2015). Descriptions of the survey design and data collection processes are available in detail elsewhere (Grant \& Dawson, 2006; Grant, Dawson, Stinson, Chou, Kay, \& Pickering, 2003). Individuals that selected sexual assault (either in childhood or adulthood) as their index trauma - in relation to symptoms of traumatic stress -, were included in the current analyses $(n=1054)$. It was necessary to model ICD-11 PTSD and CPTSD; as it is not possible to generate class membership probabilities for cases where no data exists, missing data can and was accommodated for in the LCA however each case required at least one datum to facilitate model estimation therefore individuals with missing data across all PTSD items were excluded resulting in a sample size of $n=956$.

Most of the sample was female $(91.1 \%)$, with a mean age of 41.85 years $(S D=$ 12.96). The age one recalled first experiencing sexual assault ranged from 3 to 60 years; $\leq 12$ 
years $(61.1 \%), 13-18$ years $(23.6 \%), \geq 19$ years $(15.3 \%)$. The frequency of sexual assault was as follows; 1 incident (39.5\%), 2 incidents (14.6\%), between 3 to 98 incidents (45.9\%). No formal schooling was reported by $0.1 \%, 12.2 \%$ attended but did not complete high school, $21.8 \%$ completed high school, $44.2 \%$ obtained a Graduate Equivalency Degree or some college/technical degree, and $21.7 \%$ completed a bachelor's degree or post graduate degree. Self-reported race was as follows; White non- Hispanic (60\%), Black, non-Hispanic (19.85\%), American Indian/Alaska Native, non- Hispanic (2\%), Asian/Native Hawaiian/other Pacific Islander, non-Hispanic (1.6\%), Hispanic, any race (16.6\%). Information on total personal income was also obtained; $\leq \$ 19,999(51.3 \%), \$ 20,000-\$ 69,999(44.3 \%), \geq$ $\$ 70,000(4.4 \%)$.

\subsection{Measures}

\subsubsection{ICD-11 PTSD and CPTSD}

Items utilised to model ICD-11 PTSD and CPTSD were selected from two measures from the Alcohol Use Disorder and Associated Disabilities Interview Schedule-DSM-IV Version (AUDADIS-IV) (Hasin, Goodwin, Stinson, \& Grant, 2005). From the AUDADIS PTSD scale items were selected to represent all three ICD-11 PTSD symptom clusters and two of the DSO symptom clusters (affective dysregulation and disturbances in relationships)

(see Table 1). Items were scored as "Yes/presence" (1) or "No/absence" (0). To represent the final DSO symptom cluster, Negative Self-Concept (NSC), two items were selected from the AUDADIS-IV 'low mood' scale (see Table 1). Items were coded as "Yes/presence" (1) or "No/absence" (0). Both NSC items were preceded by low mood screeners also scored "Yes/presence" (1) or "No/absence" (0) (i.e. individuals had to answer yes to one of these two items to go onto have NSC items assessed); ' Since your last interview, have you ever had a time when you felt sad, blue, depressed or down most of the time for at least 2 weeks?', 
and 'Since your last interview, have you ever had a time, lasting at least 2 weeks, when you didn't care about the things that you usually cared about, or when you didn't enjoy the things you usually enjoyed?". Those who responded "No" to the screener items could not respond to the NSC items, responses for these were therefore coded as "No/absence" (0). The AUDADIS-IV depression and PTSD scales have demonstrated good test-retest reliability and internal consistency (Grant et al., 2003; Ruan et al., 2008). The wording of each item is presented in Table 1.

[Insert Table 1 here]

\subsubsection{Borderline Personality Disorder}

The AUDADIS-IV also contains a measure which assesses for DSM-IV BPD (American Psychiatric Association, 2000). The AUDADIS-IV BPD scale has demonstrated good test-retest reliability and internal consistency (Ruan et al., 2008). Nine items were selected from this scale (see Table 1). Items were scored as 'Yes/presence' (1) or “No/absence'” (0).

\subsubsection{Child maltreatment}

Five types of child maltreatment were examined; sexual abuse, physical abuse, emotional abuse, physical neglect and emotional neglect. The 19 items assessing for these experiences were scored on a 5-point Likert-scale of "Never $=1$ "' to "'Always $=5$ "' (see Table 2), all items assessed for incidents that occurred prior to age 18. For data analyses, total scores for each trauma type were calculated and dichotomised, those who did not endorse a particular type of child maltreatment were coded as "No/absence" $(0)$ all other scores were coded as "Yes/presence" (1). A cumulative child maltreatment variable was created by 
summing the various dichotomised child maltreatment variables. This child abuse/neglect scale has excellent reliability $(\geq 0.75)$ (Hasin \& Grant, 2015).

\section{[Insert Table 2 here]}

\subsection{Analyses}

\subsubsection{Latent class analysis}

LCA utilises observed categorical data to uncover distinct groups of individuals based on patterns of symptom endorsement (presence/absence). In total, 21 symptoms were specified in the LCA; 6 items representing PTSD, 6 items representing DSO and 9 items representing BPD. Five latent class models were tested - a two-class through to a six-class model. To identify the optimal class solution a number of statistical fit indices were compared; the Bayesian Information Criterion [BIC; Schwarz (1978)], the Sample-Size Adjusted BIC [SSA-BIC; (Sclove, 1987)], and the Akaike Information Criterion [AIC; (Akaike, 1987)]. Lower values indicate the correct number of classes, with evidence to suggest that the BIC is the best fitting information criterion for identifying the optimal class solution (Nylund, Asparouhov, \& Muthén, 2007). The Lo-Mendell-Rubin adjusted likelihood ratio test [LMR-A; (Lo, Mendell, \& Rubin, 2001)] was examined to compare the increasing number of class solutions, where a non-significant LMR-A $(p>0.05)$ occurs it is suggested that a solution with one fewer class should be accepted. Additionally, entropy values were used to discriminate between class solutions with higher values indicating better differentiation of classes. This analysis was conducted using Mplus 7.1 (Muthén, 2012).

\subsubsection{Regression analyses}

Multi-nominal logistic regression assessed whether different types of child maltreatment and cumulative child maltreatment discriminated between the classes identified 
in the LCA. The following variables were controlled for in the regression models; Age, sex (0 $=$ male, $1=$ female), age when first sexually assaulted, number of times one was sexually assaulted, education $(1=$ no formal schooling to $14=$ completed masters degree or higher $)$, race $(1=$ white non-Hispanic; 2 = Black, non-Hispanic; 3 = American Indian/Alaska Native, non-Hispanic; 4 = Asian/Native Hawaiian/Other Pacific Islander, non-Hispanic; $5=$ Hispanic, any race $)$ and personal income $(0=$ No personal income to $17=\$ 100,000$ or more $)$.

\subsubsection{Diagnostic rates}

ICD-11 PTSD and CPTSD were estimated based on the ICD-11 diagnostic guidelines (Maercker et al., 2013). A diagnosis of PTSD requires that a person endorses one of two symptoms from the re-experiencing, avoidance, and sense of threat clusters. A diagnosis of CPTSD requires that a person screens positive for PTSD and also endorses one of two symptoms from the affective dysregulation, negative self-concept, and disturbed relationships clusters. The ICD-11 taxonomic structure only permits a diagnosis of either CPTSD or PTSD; if an individual receives a diagnosis for CPTSD then that person does not qualify for a diagnosis of PTSD. ICD-11 trauma diagnoses also require the presence of functional impairment, however, this could not be assessed based on the AUDADIS-IV measure that is contained in the NESARC-II therefore diagnostic rates were based solely on symptom endorsement criteria. BPD diagnosis were estimated based on DSM-IV diagnostic criteria; individuals endorsing five or more of the nine BPD symptoms screened positive for BPD.

\section{Results}

\subsection{Descriptive statistics}

The frequency of reporting PTSD, DSO and BPD items are presented in Table 1. In total, $41.3 \%(n=581)$ screened positive for a PTSD diagnosis, $19.5 \%(n=186)$ for a CPTSD 
diagnosis, and $16.8 \%(n=161)$ for a BPD diagnosis. Of those with a BPD diagnosis, approximately half also had a CPTSD diagnosis $(52.2 \%, n=84)$, and approximately a quarter had a PTSD diagnosis $(24.2 \%, n=39)$. CPTSD and BPD diagnoses did not differ by sex, whereas PTSD diagnosis significantly differed $\left(\chi^{2}(1, N=956)=18.86, p<.001\right)$ with females $(62.9 \%)$ having higher rates of PTSD compared to males.

The most commonly reported form of childhood maltreatment was childhood sexual abuse (75.4\%), followed by emotional neglect (74.5\%), emotional abuse (70.7\%), physical abuse $(62.9 \%)$ and physical neglect (54.3\%). A minority of the sample experienced no form of child maltreatment (4.3\%), 12\% experienced one type of child maltreatment, $13.8 \%$ experience two types of maltreatment, $14.6 \%$ experienced three types of maltreatment, $21.8 \%$ experienced four types of maltreatment and $33.5 \%$ of the sample experienced five types of maltreatment.

\section{[Insert Table 3 here]}

\subsection{Latent class analysis}

The fit indices of the class models are presented in Table 2. The latent class models for 3 through to 5 classes all yielded non-significant LMR-A results. The five-class model had the lowest BIC value and was therefore selected as the best fitting model (see Figure 1).

Class 1 had a high probability of endorsing the PTSD and DSO symptoms, with the exception of the negative self-concept symptoms, and a low probability of endorsing all BPD symptoms. This class was labelled the 'CPTSD class'. Class 2 had a high probability of endorsing PTSD symptoms and a low probability of endorsing DSO symptoms (except for a high probability of endorsing the affective dysregulation items 'becoming easily upset' and moderate probability of endorsing 'feeling emotional distant from others') and a low probability of endorsing BPD symptoms. This class was labelled the 'PTSD class'. Class 3 had a high probability of endorsing all items for PTSD, DSO and BPD (except for the item 
'unstable self'). This class was therefore labelled the 'comorbid class'. Class 4 had a high probability of endorsing PTSD and BPD symptoms (except for the item 'unstable self') but a relatively low probability of endorsing DSO symptoms, this class was labelled the 'BPDPTSD' class. Class 5 had a low probability of endorsing all symptoms except for moderately endorsing avoidance of thoughts. This class was labelled the 'low symptom class'. An acceptable entropy value of 0.839 indicated that there was adequate discrimination between the resultant classes.

[Insert Figure 1 here]

The frequency of childhood trauma exposure across the resultant classes is presented in Table 4. The 'comorbid class' were more likely to report childhood physical abuse, physical neglect and emotional abuse compared to the 'PTSD class' and 'low symptom class'. The 'comorbid class' also were more likely to report childhood sexual abuse compared to the 'low symptom class'. The 'CPTSD class' were more likely to report emotional neglect compared to the 'PTSD class' and the 'low symptom class'. It was notable that a similar proportion of both Class 1 and Class 4 experienced emotional neglect but that only Class 1 statistically differed from Classes 2 and 3. It is likely that this difference was attributable to limited statistical power as a consequence of the smaller sample size of Class 4 .

[Insert Table 4 here]

\subsection{Regression Analysis}

Multinomial logistic regression was utilised to assess if different kinds of child maltreatment and cumulative child maltreatment discriminated between the resultant classes. All statistically significant findings from the regression analyses are detailed here.

\subsubsection{Child maltreatment types}

The model testing different types of child maltreatment as predictors of class membership was statistically significant when the 'low symptom class' was set as the 
reference category $\left(\chi^{2}(48)=180.94, p<.001\right)$. The odds ratio for childhood physical neglect $(\mathrm{OR}=1.74, p=.040, \mathrm{CI}=1.02-2.95)$, indicated an increased risk of 'CPTSD class' membership. The odds ratios for childhood physical neglect $(\mathrm{OR}=2.40, p=.002, \mathrm{CI}=1.36$ $-4.23)$, childhood verbal abuse $(\mathrm{OR}=3.13, p=.002, \mathrm{CI}=1.52-6.47)$ and childhood sexual abuse $(\mathrm{OR}=2.91, p=.023, \mathrm{CI}=1.21-4.68)$ indicated increased risk for 'comorbid class' membership.

When the 'CPTSD class' was set as the reference category, childhood verbal abuse $(\mathrm{OR}=2.51, p=.016, \mathrm{CI}=1.185-5.318)$ increased the risk for 'comorbid class' membership.

\subsubsection{Cumulative child maltreatment}

The model testing the effect of cumulative child maltreatment as a predictor of class membership was statistically significantly $\left(\chi^{2}(48)=183.15, p<.001\right)$ when the 'low symptom class' was set as the baseline category. The odds ratio for experiencing five types of child maltreatment indicated an increased risk for membership to the 'CPTSD class' as compared to the 'low symptom class' $(\mathrm{OR}=4.65, p=.012, \mathrm{CI}=1.39-15.50)$. Child maltreatment evidenced a dose response relationship with the 'comorbid class', experiencing four types of maltreatment $(\mathrm{OR}=9.41, p=.007, \mathrm{CI}=1.85-44.77)$ and five types of maltreatment $(\mathrm{OR}=15.97, p=.001, \mathrm{CI}=3.10-82.40)$ increased the risk of membership with the 'comorbid class' as compared to the 'low symptom class'.

\section{Discussion}

This study employed LCA to assess if CPTSD and BPD symptomatology were distinguishable among a general population sample characterised by sexual trauma - a context in which both disorders are likely to manifest. In contrast to our first hypothesis, a distinct 
BPD class was not identified. Separate PTSD and CPTSD classes were identified but two classes were characterised by BPD and trauma-symptoms; (1) a BPD-PTSD class, denoted by a high probability of endorsing BPD and PTSD symptoms but a relatively lower probability of endorsing DSO symptoms; and (2) a comorbid class, denoted by a high probability of endorsing all measured symptoms. Childhood physical neglect was the only maltreatment type that predicted membership to the CPTSD class. Further, the CPTSD class was associated with cumulative childhood trauma exposure.

The LCA results provide evidence consistent with the ICD-11's recognition of CPTSD as a distinct trauma response profile. As it was possible for a CPTSD symptom profile to manifest in the absence of BPD symptomology, this finding would indicate that CPTSD does not represent an amalgam of BPD/PTSD comorbidity. Findings from the current analysis are thus consistent with previous research indicating that CPTSD and BPD symptomatology are distinguishable (Cloitre et al., 2014; Knefel et al., 2016). Although both disorders encompass symptoms that reflect disruption to self-concept, interpersonal relationships, and affective regulation capacity, phenomenological distinctions likely separate CPTSD from BPD (i.e. self-harm may be more characteristic of BPD as opposed to CPTSD) (Cloitre et al., 2014).

However, borderline symptoms did not emerge independently from the traumatic stress symptoms. This may likely have been due to the restricted trauma status of the sample under investigation. Trauma exposure is not a prerequisite for BPD diagnosis, BPD symptomology can manifest in a range of other contexts, for example, via predisposing developmental vulnerabilities or other developmental experiences, such as disruptions in formative relationships (i.e., due to incompatible personalities of the primary caregiver and child; Lieb et al., 2004; Lyons-Ruth \& Jacobvitz, 2008; Scheiderer et al., 2015; Zanarini \& Frankenburg, 1997; Zanarini et al., 1997). BPD symptoms may have emerged independently 
of traumatic stress symptoms had the sample not been stratified by trauma exposure.

Similarly, Cloitre et al., (2014) reported a 'BPD class' that endorsed traumatic stress symptoms which again may be attributable to the restricted nature of the sample under investigation (i.e. treatment seeking sample with a history of child abuse). Importantly however, the aim of the current analysis was to test whether CPTSD symptomology was distinguishable from BPD symptomology in a specific trauma context where both phenomena were likely to manifest. In this particular context, BPD symptoms did not emerge separately from the trauma-related symptoms modelled thus comorbidity between these phenomena would understandably be expected in the general population (Frias \& Palma, 2015; Grant et al., 2008; Pagura et al., 2010; Scheiderer et al., 2015).

Consistent with research concerning the prevalence of sexual violence, the majority of the sample first experienced sexual assault before the age of 18 and reported more than one incident of sexual assault along with multiple types of child maltreatment (Basile \& Smith, 2011; Finkelhor et al., 2013). Cumulative childhood trauma and physical neglect predicted membership to the CPTSD class as compared to the low symptom class. This finding is consistent with research suggesting that interpersonal victimisation represents a key risk factor for the development of CPTSD (Ben-Ezra et al., 2018; Cloitre et al., 2013; Gilbar et al., 2018; Hyland et al., 2017; Karatzias et al., 2016; Shevlin et al., 2017) and literature illustrating that neglect plays a unique role in the development of psychopathology (e.g. Teicher \& Samon, 2016). However, cumulative trauma and various forms of maltreatment also predicted membership to the comorbid class. Although cumulative trauma predicted membership to the CPTSD class and the comorbid class, emotional abuse was the only form of maltreatment that predicted membership to the comorbid class when compared to the CPTSD class. This result is consistent with research suggesting that the effect of child maltreatment may not be additive, emotional abuse may constitute a more potent factor in the 
development of comorbid symptomology (Spinazzola et al., 2014). Overall, the findings of the regression analyses would suggest that, in the context of sexual trauma, child maltreatment did not readily differentiate a CPTSD symptom profile from the other trauma response profiles. It may be the case that psychosocial correlates such as personality traits or coping styles better distinguish CPTSD from other trauma response profiles (Ford \& Courtois, 2014; Resick et al., 2012).

While CPTSD and BPD may have potential symptom overlap, the clinical phenomenology of these syndromes requires different treatment considerations (Cloitre et al., 2013; Ford \& Courtois, 2014). Key treatment goals for CPTSD focus on promoting social engagement, self-concept, and reviewing the meaning of trauma memories (Cloitre, Cohen, \& Koenen, 2011). In contrast, key goals for BPD treatment focus on a reduction of selfinjurious and suicidal behaviours, increasing a stable sense of self, and a reduction in dependency on others (Linehan, 1993). Without formal recognition of a CPTSD diagnosis, clinicians may be forced to artificially graft mechanisms associated with aspects of PTSD and BPD to address core CPTSD symptoms (Ford \& Courtois, 2014). As evidence is mounting to suggest that the clinical phenomenology for these disorders differs, formal recognition of CPTSD as a distinct diagnostic entity could reduce the risk of over or underdiagnoses and sub-optimal treatment formulations (Herman, 1992).

This study had several limitations. Firstly, trauma symptoms were modelled from scales not specifically designed to assess CPTSD. Hypoactive emotion regulation symptoms relating to emotion numbing were not available in the data set such items have been hypothesised to comprise a key feature of CPTSD (i.e. Karatzias et al., 2016). Items selected to represent the NSC cluster of CPTSD symptoms, while consistent with ICD-11 proposals, were anchored to primary depression screeners that may have restricted endorsement of these items. Several investigations evaluating the validity of CPTSD have employed the same item 
selection strategy (Brewin et al., 2017). While this finding may indicate a methodological effect related to the use of preceding screener items, it could also question the selection of worthlessness as representing NSC, perceiving the self as damaged or a failure may be more representative of NSC, but such items were unavailable in the dataset. Secondly, although the frequency and age of onset of sexual assault were controlled for in the regression analyses, other potentially traumatic events which may have occurred throughout the respondents' life span were not included. Lastly, as the sample was comprised of victims of sexual trauma, the generalizability of the findings may be limited compared to other trauma exposed populations.

Overall, this study demonstrates that CPTSD symptoms are distinguishable from BPD symptoms in a distinct trauma context (i.e. among victims of sexual trauma). Conceptually, formal recognition of CPTSD as a distinct diagnostic entity could afford a valuable contribution towards increasing the precision of assessment and treatment. Further investigation is necessary to assess the discriminant validity of the CPTSD in relation to BPD across samples characterised by varying levels of trauma exposure and utilising standardised measures of ICD-11 CPTSD.

\section{Declaration of interest}

None.

\section{Acknowledgements}

This work was supported by funding from the European Commission's Horizon 2020 research and innovation programme, under the Marie Skłodowska-Curie grant agreement No 722523 to the Collaborative Network for Training and Excellence in Psychotraumatology (CONTEXT). 


\section{References}

American Psychiatric Association. (2000). DSM-IV-TR: Diagnostic and statistical manual of mental disorders, text revision. Washington, DC: American Psychiatric Association, 75, 78-85.

Akaike, H. (1987). Factor analysis and AIC Selected Papers of Hirotugu Akaike (pp. 371386): Springer, New York, NY.

Basile, K. C., \& Smith, S. G. (2011). Sexual Violence Victimization of Women: Prevalence, Characteristics, and the Role of Public Health and Prevention. American Journal of Lifestyle Medicine, 5, 407-417. http://dx.doi.org/10.1177/1559827611409512

Ben-Ezra, M., Karatzias, T., Hyland, P., Brewin, C. R., Cloitre, M., Bisson, J. I., . . Shevlin, M. (2018). Posttraumatic stress disorder (PTSD) and complex PTSD (CPTSD) as per ICD-11 proposals: A population study in Israel. Depression and Anxiety, 35, 264-274. http://dx.doi.org/10.1002/da.22723

Brewin, C. R., Cloitre, M., Hyland, P., Shevlin, M., Maercker, A., Bryant, R. A., . . Reed, G. M. (2017). A review of current evidence regarding the ICD-11 proposals for diagnosing PTSD and complex PTSD. Clinical Psychology Review, 58, 1-15. https://doi.org/10.1016/j.cpr.2017.09.001

Cloitre, M., Cohen, L. R., \& Koenen, K. C. (2011). Treating survivors of childhood abuse: Psychotherapy for the interrupted life: Guilford Press.

Cloitre, M., Garvert, D. W., Brewin, C. R., Bryant, R. A., \& Maercker, A. (2013). Evidence for proposed ICD-11 PTSD and complex PTSD: a latent profile analysis. European Journal of Psychotraumatology, 4. http://dx.doi.org/10.3402/ejpt.v4i0.20706 
Cloitre, M., Garvert, D. W., Weiss, B., Carlson, E. B., \& Bryant, R. A. (2014). Distinguishing PTSD, Complex PTSD, and Borderline Personality Disorder: A latent class analysis. European Journal of Psychotraumatology, 5. http://dx.doi.org/10.3402/ejpt.v3405.25097

de Aquino Ferreira, L. F., Queiroz Pereira, F. H., Neri Benevides, A. M. L., \& Aguiar Melo, M. C. (2018). Borderline personality disorder and sexual abuse: A systematic review. Psychiatry Research, 262, 70-77. http://dx.doi.org/10.1016/j.psychres.2018.01.043

Finkelhor, D., Turner, H. A., Shattuck, A., \& Hamby, S. L. (2013). Violence, crime, and abuse exposure in a national sample of children and youth: An update. JAMA Pediatrics, 167, 614-621. http://dx.doi.org/10.1001/jamapediatrics.2013.42

Ford, J. D., \& Courtois, C. A. (2014). Complex PTSD, affect dysregulation, and borderline personality disorder. Borderline Personality Disorder and Emotion Dysregulation, 1, 9. http://dx.doi.org/10.1186/2051-6673-1-9

Frias, A., \& Palma, C. (2015). Comorbidity between post-traumatic stress disorder and borderline personality disorder: a review. Psychopathology, 48, 1-10. http://dx.doi.org/10.1159/000363145

Gilbar, O., Hyland, P., Cloitre, M., \& Dekel, R. (2018). ICD-11 complex PTSD among Israeli male perpetrators of intimate partner violence: Construct validity and risk factors. Journal of Anxiety Disorders, 54, 49-56. https://doi.org/10.1016/j.janxdis.2018.01.004

Grant, B. F., Chou, S. P., Goldstein, R. B., Huang, B., Stinson, F. S., Saha, T. D., . . Ruan, W. J. (2008). Prevalence, Correlates, Disability, and Comorbidity of DSM-IV Borderline Personality Disorder: Results from the Wave 2 National Epidemiologic Survey on Alcohol and Related Conditions. The Journal of Clinical Psychiatry, 69, $533-545$. 
Grant, B. F., \& Dawson, D. A. (2006). Introduction to the national epidemiologic survey on alcohol and related conditions. Alcohol Health \& Research World, 29, 74.

Grant, B. F., Dawson, D. A., Stinson, F. S., Chou, P. S., Kay, W., \& Pickering, R. (2003). The Alcohol Use Disorder and Associated Disabilities Interview Schedule-IV (AUDADIS-IV): reliability of alcohol consumption, tobacco use, family history of depression and psychiatric diagnostic modules in a general population sample. Drug Alcohol Dependence, 71, 7-16.

Harned, M. S., Rizvi, S. L., \& Linehan, M. M. (2010). Impact of co-occurring posttraumatic stress disorder on suicidal women with borderline personality disorder. The American Journal of Psychiatry, 167, 1210-1217.

http://dx.doi.org/10.1176/appi.ajp.2010.09081213

Hasin, D. S., Goodwin, R. D., Stinson, F. S., \& Grant, B. F. (2005). Epidemiology of major depressive disorder: results from the National Epidemiologic Survey on Alcoholism and Related Conditions. Archives of General Psychiatry, 62, 1097-1106. http://dx.doi.org/10.1001/archpsyc.62.10.1097

Hasin, D. S., \& Grant, B. F. (2015). The National Epidemiologic Survey on Alcohol and Related Conditions (NESARC) Waves 1 and 2: review and summary of findings. Social Psychiatry and Psychiatric Epidemiology, 50, 1609-1640. http://dx.doi.org/10.1007/s00127-015-1088-0

Heffernan, K., \& Cloitre, M. (2000). A comparison of posttraumatic stress disorder with and without borderline personality disorder among women with a history of childhood sexual abuse: etiological and clinical characteristics. The Journal of Nervous and Mental Disorder, 188, 589-595.

Herman, J. L. (1992). Complex PTSD: A syndrome in survivors of prolonged and repeated trauma. Journal of Traumatic Stress, 5, 377-391. 
Hyland, P., Murphy, J., Shevlin, M., Vallieres, F., McElroy, E., Elklit, A., . . Cloitre, M. (2017). Variation in post-traumatic response: the role of trauma type in predicting ICD-11 PTSD and CPTSD symptoms. Social Psychiatry and Psychiatric Epidemiology, 52, 727-736. http://dx.doi.org/10.1007/s00127-017-1350-8

Karatzias, T., Shevlin, M., Fyvie, C., Hyland, P., Efthymiadou, E., Wilson, D., . . Cloitre, M. (2016). An initial psychometric assessment of an ICD-11 based measure of PTSD and complex PTSD (ICD-TQ): Evidence of construct validity. Journal of Anxiety Disorders, 44, 73-79. http://dx.doi.org/10.1016/j.janxdis.2016.10.009

Knefel, M., Tran, U. S., \& Lueger-Schuster, B. (2016). The association of posttraumatic stress disorder, complex posttraumatic stress disorder, and borderline personality disorder from a network analytical perspective. Journal of Anxiety Disorders, 43, 7078. http://dx.doi.org/10.1016/j.janxdis.2016.09.002

Lieb, K., Zanarini, M. C., Schmahl, C., Linehan, M. M., \& Bohus, M. (2004). Borderline personality disorder. The Lancet, 364, 453-461. http://dx.doi.org/10.1016/S01406736(04)16770-6

Linehan, M. (1993). Cognitive-behavioral treatment of borderline personality disorder: Guilford press.

Lo, Y., Mendell, N. R., \& Rubin, D. B. (2001). Testing the number of components in a normal mixture. Biometrika, 88, 767-778.

Lyons-Ruth, K., \& Jacobvitz, D. (2008). Attachment disorganization: Genetic factors, parenting contexts, and developmental transformation from infancy to adulthood. Infant Mental Health Journal, 29, 203-218. http://dx.doi.org/10.1002/imhj.20173

Maercker, A., Brewin, C. R., Bryant, R. A., Cloitre, M., van Ommeren, M., Jones, L. M., .. . Reed, G. M. (2013). Diagnosis and classification of disorders specifically associated 
with stress: proposals for ICD-11. World Psychiatry, 12, 198-206. http://dx.doi.org/10.1002/wps.20057

Maercker, A., Hecker, T., Augsburger, M., \& Kliem, S. (2018). ICD-11 Prevalence Rates of Posttraumatic Stress Disorder and Complex Posttraumatic Stress Disorder in a German Nationwide Sample. The Journal of Nervous and Mental Disorders, 206, 270-276. http://dx.doi.org/10.1097/nmd.0000000000000790

Muthén, L. (2012). Mplus User’s Guide. Los Angeles, CA: Muthén \& Muthén 1998-2010.

Nylund, K. L., Asparouhov, T., \& Muthén, B. O. (2007). Deciding on the number of classes in latent class analysis and growth mixture modeling: A Monte Carlo simulation study. Structural equation modeling, 14, 535-569.

https://doi.org/10.1080/10705510701575396

Pagura, J., Stein, M. B., Bolton, J. M., Cox, B. J., Grant, B., \& Sareen, J. (2010). Comorbidity of borderline personality disorder and posttraumatic stress disorder in the U.S. population. Journal of Psychiatric Research, 44, 1190-1198. http://dx.doi.org/10.1016/j.jpsychires.2010.04.016

Resick, P. A., Bovin, M. J., Calloway, A. L., Dick, A. M., King, M. W., Mitchell, K. S., . . Wolf, E. J. (2012). A critical evaluation of the complex PTSD literature: implications for DSM-5. Journal of Traumatic Stress, 25, 241-251. http://dx.doi.org/10.1002/jts.21699

Ruan, W. J., Goldstein, R. B., Chou, S. P., Smith, S. M., Saha, T. D., Pickering, R. P., . . Grant, B. F. (2008). The alcohol use disorder and associated disabilities interview schedule-IV (AUDADIS-IV): reliability of new psychiatric diagnostic modules and risk factors in a general population sample. Drug Alcohol Dependence, 92, 27-36. http://dx.doi.org/10.1016/j.drugalcdep.2007.06.001

Teicher, M. H., \& Samson, J. A. (2016). Annual Research Review: Enduring neurobiological 
effects of childhood abuse and neglect. Journal of Child Psychology and Psychiatry and Allied Disciplines, 57(3), 241-266. http://doi: 10.1111/jcpp.12507

Scheiderer, E. M., Wood, P. K., \& Trull, T. J. (2015). The comorbidity of borderline personality disorder and posttraumatic stress disorder: revisiting the prevalence and associations in a general population sample. Borderline Personality Disorder and Emotion Dysregulation, 2, 11. http://dx.doi.org/10.1186/s40479-015-0032-y

Schwarz, G. (1978). Estimating the dimension of a model. The annals of statistics, 6(2), 461464.

Sclove, S. L. (1987). Application of model-selection criteria to some problems in multivariate analysis. Psychometrika, 52, 333-343.

Shevlin, M., Dorahy, M., Adamson, G., \& Murphy, J. (2007). Subtypes of borderline personality disorder, associated clinical disorders and stressful life-events: a latent class analysis based on the British Psychiatric Morbidity Survey. British Journal of Clinical Psychology, 46, 273-281.

Shevlin, M., Hyland, P., Karatzias, T., Fyvie, C., Roberts, N., Bisson, J. I., . . Cloitre, M. (2017). Alternative models of disorders of traumatic stress based on the new ICD-11 proposals. Acta Psychiatrica Scandinavica, 135, 419-428. http://dx.doi.org/10.1111/acps.12695

Spinazzola, J., Hodgdon, H., Liang, L., Ford, J. D., Layne, C., Pynoos, R., . . Kisiel, C. L. (2014). Unseen wounds: The contribution of psychological maltreatment to child and adolescent mental health and risk outcomes. Psychological Trauma: Theory, Research, Practice \& Policy, 6, 518-528.

Zanarini, M. C., \& Frankenburg, F. R. (1997). Pathways to the development of borderline personality disorder. Journal of Personality Disorders, 11, 93-104. https://doi.org/10.1521/pedi.1997.11.1.93 
Zanarini, M. C., Frankenburg, F. R., Dubo, E. D., Sickel, A. E., Trikha, A., Levin, A., \& Reynolds, V. (1998). Axis I comorbidity of borderline personality disorder. The American Journal of Psychiatry, 155, 1733-1739. http://dx.doi.org/10.1176/ajp.155.12.1733

Zanarini, M. C., Williams, A. A., Lewis, R. E., Reich, R. B., Vera, S. C., Marino, M. F., . . Frankenburg, F. R. (1997). Reported pathological childhood experiences associated with the development of borderline personality disorder. The American Journal of Psychiatry, 154, 1101-1106. http://dx.doi.org/10.1176/ajp.154.8.1101

Zlotnick, C., Franklin, C. L., \& Zimmerman, M. (2002). Is comorbidity of posttraumatic stress disorder and borderline personality disorder related to greater pathology and impairment? The American Journal of Psychiatry, 159, 1940-1943. http://dx.doi.org/10.1176/appi.ajp.159.11.1940 
Table 1.

Frequency of endorsing PTSD and DSO items for the sample ( $n=956)$

\begin{tabular}{|c|c|c|c|}
\hline \multicolumn{2}{|c|}{ Symptoms } & Items & \multirow[t]{2}{*}{$\%$} \\
\hline \multicolumn{3}{|l|}{ PTSD } & \\
\hline \multirow[t]{2}{*}{$\mathrm{RE}$} & Flashback & Have unpleasant or bad dreams about it? & 72.8 \\
\hline & Nightmares & $\begin{array}{l}\text { Feel that you were reliving (that/that worst) event or that it } \\
\text { was happening all over again? }\end{array}$ & 59.5 \\
\hline \multirow[t]{2}{*}{ AV } & $\begin{array}{l}\text { Avoidance } \\
\text { Thoughts }\end{array}$ & $\begin{array}{l}\text { Try to stop thinking about or feeling anything about (that/that } \\
\text { worst) event? }\end{array}$ & 86.8 \\
\hline & $\begin{array}{l}\text { Avoidance } \\
\text { Places }\end{array}$ & $\begin{array}{l}\text { Stay away from going places/doing things/seeing people that } \\
\text { might bring back memories of the event? }\end{array}$ & 55.3 \\
\hline \multirow[t]{2}{*}{ SOT } & Hypervigilance & $\begin{array}{l}\text { Find yourself being more watchful or alert even though there } \\
\text { was no real need to be? }\end{array}$ & 70.9 \\
\hline & Startle & $\begin{array}{l}\text { Find that you were more jumpy or easily startled by ordinary } \\
\text { noises? }\end{array}$ & 48.0 \\
\hline \multicolumn{4}{|c|}{ 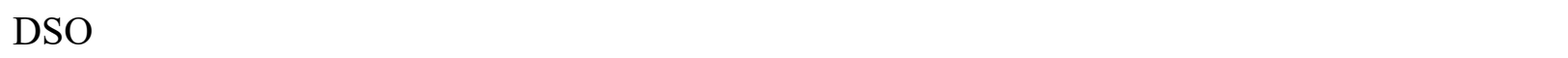 } \\
\hline \multirow[t]{2}{*}{$\mathrm{AD}$} & Easily upset & $\begin{array}{l}\text { Get very upset when you were reminded of (that/that worst) } \\
\text { event? }\end{array}$ & 72.2 \\
\hline & Anger & Find yourself getting angry or irritable more often than usual? & 46.7 \\
\hline \multirow[t]{2}{*}{ DR } & Distant & $\begin{array}{l}\text { Feel emotionally distant from other people, or cut off from } \\
\text { others? }\end{array}$ & 58.4 \\
\hline & Detached & $\begin{array}{l}\text { Feel as though you couldn't feel positive or loving towards } \\
\text { other people like you used to? }\end{array}$ & 47.4 \\
\hline \multirow[t]{2}{*}{ NSC } & Worthless & Feel worthless nearly all the time for at least 2 weeks? & 23.1 \\
\hline & Guilty & $\begin{array}{l}\text { Feel guilty about things you normally wouldn't feel guilty } \\
\text { about, most of the time for at least } 2 \text { weeks? }\end{array}$ & 25.1 \\
\hline \multicolumn{4}{|c|}{ 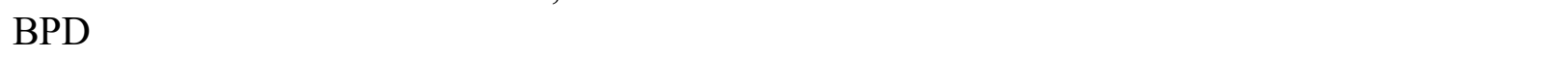 } \\
\hline & Frantic & $\begin{array}{l}\text { Have you often become frantic when you thought that } \\
\text { someone you really cared about was going to leave you? }\end{array}$ & 27.8 \\
\hline & $\begin{array}{l}\text { Unstable } \\
\text { relationships }\end{array}$ & $\begin{array}{l}\text { Have your relationships with people you really care about } \\
\text { had lots of extreme ups and downs? }\end{array}$ & 37.1 \\
\hline & $\begin{array}{l}\text { Unstable Sense } \\
\text { of self }\end{array}$ & $\begin{array}{l}\text { Have you been so different with different people or in } \\
\text { different situations that you sometimes don't know who you } \\
\text { really are? }\end{array}$ & 6.8 \\
\hline & Impulsiveness & Have you often done things impulsively? & 30.4 \\
\hline & Self-harm & Have you tried to hurt or kill yourself, or threatened to do so? & 17.8 \\
\hline & Empty & Have you often felt empty inside? & 22.6 \\
\hline & Temper & $\begin{array}{l}\text { Have you often had temper outburst or gotten so angry that } \\
\text { you lose control? }\end{array}$ & 30.4 \\
\hline & Mood changes & Have you had lot of sudden mood changes? & 18.4 \\
\hline & $\begin{array}{l}\text { Paranoid } \\
\text { dissociation }\end{array}$ & $\begin{array}{l}\text { Have you gotten suspicious of other people or felt spaced out } \\
\text { under a lot of stress? }\end{array}$ & 24.7 \\
\hline
\end{tabular}

Note. PTSD = Post Traumatic Stress Disorder; DSO = Disturbances in Self-Organisation; $\mathrm{BPD}=$ Borderline Personality Disorder; Re = Re-experiencing; $\mathrm{Av}=$ Avoidance; $\mathrm{SOT}=$ Sense of Threat; AD = Affective Dysregulation; DR = Disturbed Relationships; NSC = Negative Self-Concept. 
Table 2.

Items utilised to assess for child maltreatment

\begin{tabular}{|c|c|}
\hline $\begin{array}{l}\text { Childhood } \\
\text { maltreatment type }\end{array}$ & Items \\
\hline Physical Neglect & $\begin{array}{l}\text { Before age } 18 \text {, how often did parent/caregiver make you do chores } \\
\text { that were too difficult or dangerous for someone your age? } \\
\text { How often did a parent/caregiver leave you alone or unsupervised } \\
\text { before } 10 \text { years old? } \\
\text { Before age } 18 \text {, how often did you go without things you needed } \\
\text { because a parent/caregiver spent the money on themselves? } \\
\text { Before age } 18 \text {, how often did parent/caregiver male you go hungry or } \\
\text { not prepare regular meals? } \\
\text { Before age } 18 \text {, how often did parent/caregiver ignore/fail to get you } \\
\text { treatment when you were sick? }\end{array}$ \\
\hline Emotional Abuse & $\begin{array}{l}\text { Before age } 18 \text {, how often did parent/caregiver swear, insult or say } \\
\text { hurtful things to you? } \\
\text { Before age } 18 \text {, how often did parent/caregiver threaten to hit you or } \\
\text { throw something at you? } \\
\text { Before age } 18 \text {, how often did parent/caregiver make you fear that you } \\
\text { would be physical hurt or injured? }\end{array}$ \\
\hline Physical Abuse & $\begin{array}{l}\text { Before age } 18 \text {, how often did parent/caregiver push, grab, shove, slap } \\
\text { or hit you? } \\
\text { Before age } 18 \text {, how often did a parent/caregiver hit you so hard that } \\
\text { you had marks or bruises or were injured? }\end{array}$ \\
\hline Sexual Abuse & $\begin{array}{l}\text { Before age } 18 \text {, how often did adult/other person fondle/touch you in a } \\
\text { sexual way when you didn't want this/were too young to know what } \\
\text { was happening? } \\
\text { Before age } 18 \text {, how often did adult/other person have you touch them } \\
\text { in a sexual way when you didn't want this/were too young to know } \\
\text { what was happening? } \\
\text { Before age } 18 \text {, how often did adult/other person attempt sexual } \\
\text { intercourse with you when you didn't want this/were too young to } \\
\text { know what was happening? } \\
\text { Before age } 18 \text {, how often did adult/other person have sexual } \\
\text { intercourse with you when you didn't want this/were too young to } \\
\text { know what was happening? }\end{array}$ \\
\hline $\begin{array}{l}\text { Emotional } \\
\text { Neglect }\end{array}$ & $\begin{array}{l}\text { Before age } 18 \text {, felt there was someone in the family that wanted me to } \\
\text { be a success? } \\
\text { Before age } 18 \text {, felt there was someone in the family who helped me } \\
\text { feel that I was important or special? } \\
\text { Before age } 18 \text {, felt that my family was a source of strength and } \\
\text { support? } \\
\text { Before age } 18 \text {, felt that I was part of a close-knit family? } \\
\text { Before age } 18 \text {, felt that someone in my family believed in me? }\end{array}$ \\
\hline
\end{tabular}

Note. Emotional neglect items were reverse scored. 
Table 3.

Fit indices for the latent class models

\begin{tabular}{lcccccc}
\hline Model & AIC & BIC & SSABIC & Log-likelihood $(p)$ & LMR $(p)$ & Entropy \\
\hline 2 classes & 20496 & 20705 & 20569 & $-11499.893(0.0000)$ & $2572.499(0.0000)$ & 0.874 \\
3 classes & 19601 & 19917 & 19711 & $-10205.124(0.7621)$ & $933.179(0.7621)$ & 0.837 \\
4 classes & 19324 & 19747 & 19471 & $-9735.444(0.6475)$ & $318.392(0.6487)$ & 0.850 \\
$\mathbf{5}$ classes & $\mathbf{1 9 1 4 1}$ & $\mathbf{1 9 6 7 1}$ & $\mathbf{1 9 3 2 4}$ & $\mathbf{- 9 5 7 5 . 1 9 3 ( \mathbf { 0 . 7 7 9 4 } )}$ & $\mathbf{2 2 6 . 3 5 9}(\mathbf{0 . 7 7 9 4})$ & $\mathbf{0 . 8 3 9}$ \\
6 classes & 19042 & 19678 & 19262 & $\mathbf{- 9 4 6 1 . 2 6 4 ( 0 . 7 6 0 6 )}$ & $142.060(0.7606)$ & 0.822 \\
\hline
\end{tabular}

Note. AIC $=$ Akaike Information Criterion; $\mathrm{BIC}=$ Bayesian Information Criterion; ssaBIC $=$ sample size adjusted Bayesian Information Criterion; LMR = Lo-Mendell-Rubin adjusted likelihood ratio test. Best fitting CFA model in bold. 


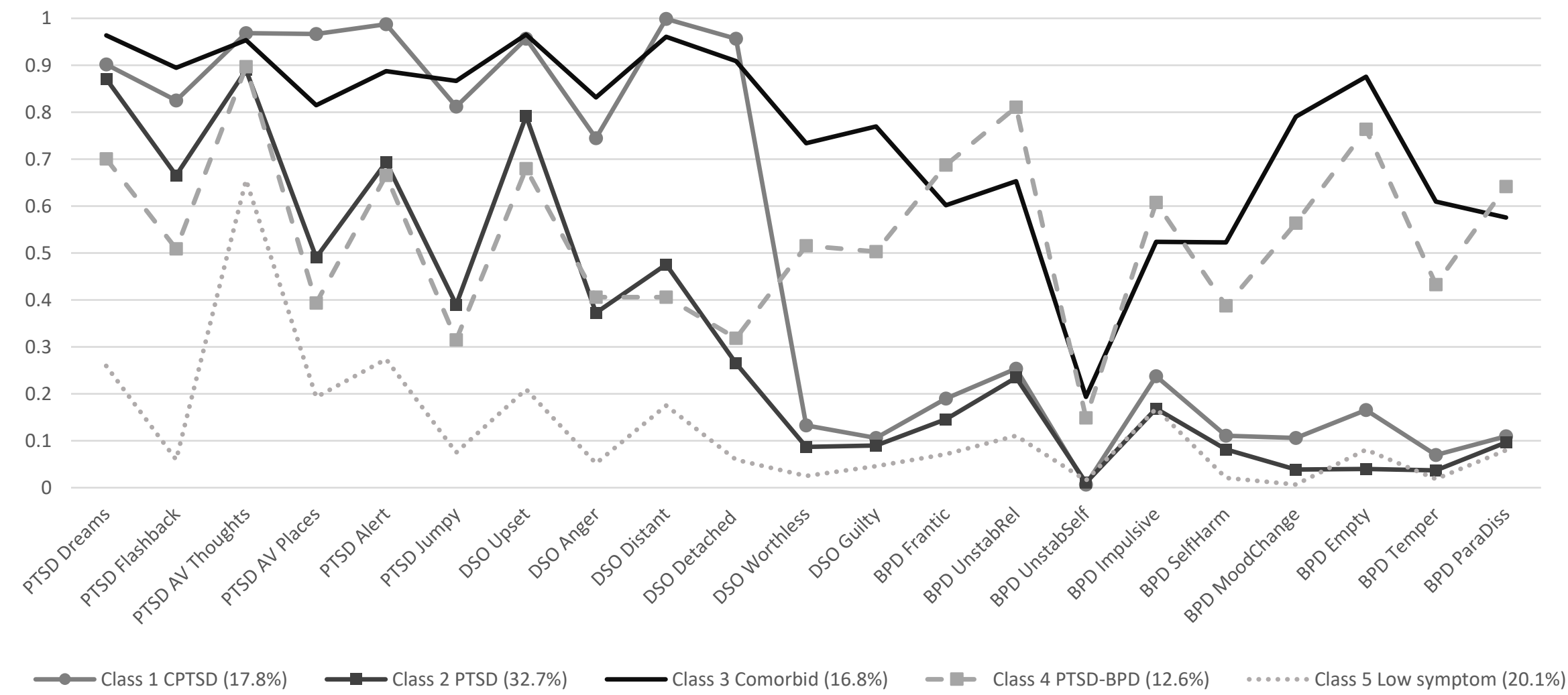

Figure 1. Symptom endorsement of PTSD, CPTSD and BPD items by class. 
Table 4.

Trauma history characteristics across class.

\begin{tabular}{lllllll}
\hline $\begin{array}{l}\text { Child } \\
\text { maltreatment }\end{array}$ & $\begin{array}{l}\text { CPTSD } \\
\text { Class 1 }\end{array}$ & $\begin{array}{l}\text { PTSD } \\
\text { Class 2 }\end{array}$ & $\begin{array}{l}\text { Low } \\
\text { symptom } \\
\text { Class 3 }\end{array}$ & $\begin{array}{l}\text { Comorbid } \\
\text { Class 4 }\end{array}$ & $\begin{array}{l}\text { BPD-PTSD } \\
\text { Class 5 }\end{array}$ & $\begin{array}{l}\text { Significance } \\
\text { test }\end{array}$ \\
\hline CSA & $78.8 \%$ & $73.2 \%$ & $68.2 \%$ & $83.9 \%$ & $76.7 \%$ & $4>3^{*}$ \\
CPA & $66.5 \%$ & $58.1 \%$ & $56.3 \%$ & $73.3 \%$ & $66.7 \%$ & $4>2,3^{*}$ \\
CEA & $72.4 \%$ & $66.5 \%$ & $62.0 \%$ & $85.1 \%$ & $74.2 \%$ & $4>2,3^{* *}$ \\
CEN & $80.6 \%$ & $70.6 \%$ & $68.8 \%$ & $80.7 \%$ & $78.3 \%$ & $1>2,3^{*}$ \\
CPN & $60.6 \%$ & $48.6 \%$ & $44.3 \%$ & $69.6 \%$ & $55.8 \%$ & $4>2,3^{* *}$ \\
\hline
\end{tabular}

Note. All Chi-Square tests were 4 degrees of freedom. $* p<0.01, * * p<0.001$. CSA $=$ Childhood Sexual Abuse; CPA $=$ Childhood Physical Abuse; $\mathrm{CEA}=$ Childhood Emotional Abuse $; \mathrm{CEN}=$ Childhood Emotional Neglect; $\mathrm{CPN}=$ Childhood Physical Neglect. 